\title{
Synthesis of a dextran based thermo-sensitive drug delivery system by gamma irradiation
}

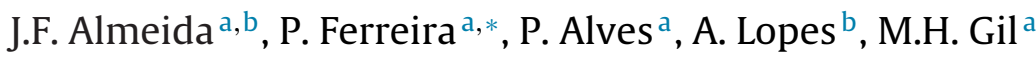 \\ a Department of Chemical Engineering, University of Coimbra, Rua Sílvio Lima, Polo II, 3030-790 Coimbra, Portugal \\ b Instituto de Tecnologia Química e Biológica, Universidade Nova de Lisboa, Apartado 127, 2781-901 Oeiras, Portugal
}

\section{A R T I C L E I N F O}

\section{Article history:}

Received 6 May 2013

Received in revised form 1 July 2013

Accepted 1 July 2013

Available online 4 July 2013

\section{Keywords:}

Dextran

Drug delivery

Gamma irradiation

\begin{abstract}
A B S T R A C T
Gamma radiation was used as the initiator/crosslinker agent for the synthesis of thermo-sensitive hydrogel networks, under the form of membranes, using dextran and $\mathrm{N}$-isopropylacrylamide. The prepared membranes were loaded with Ondansetron ${ }^{\mathrm{TM}}$, a potent antiemetic drug and tested as drug delivery systems.

The characterization of the materials was accomplished by: Attenuated Total Reflectance-Fourier Transform Infrared (ATR-FTIR) spectroscopy, elemental analysis, lower critical solution temperature (LCST) determination, swelling behaviour evaluation, determination of surface energy by contact angle measurement and drug delivery kinetics studies. Also, the influence of irradiation time and temperature on the materials properties was evaluated.
\end{abstract}

(c) 2013 Elsevier B.V. All rights reserved.

\section{Introduction}

Hydrogels are three-dimensional crosslinked networks which are able to absorb high amounts of water without suffering dissolution $[1,2]$. They can be prepared from synthetic materials like poly(ethylene glycol) or some polyacrylates such as poly(acrylic acid) [3]; from natural polymers such as dextran [4], alginate [5] and chitosan [6] and even from a mixture of synthetic and natural materials $[7,8]$. Due to their different characteristics, namely hydrophilicity, variety of composition and biocompatibility, hydrogels have been frequently used as biomaterials [9-11]. Currently, the ability of some hydrogels to respond to external stimuli, namely $\mathrm{pH}$ and temperature has been explored by researchers. This responsive behaviour is now allowing the enlargement of the hydrogels applications to several areas of medicine [12-14] with a special emphasis in drug release and delivery.

Preparation of hydrogels can be achieved by using different techniques. High energy radiations such as gamma radiation and electron beam have been previously used to prepare polysaccharide based hydrogels [15]. The simultaneous irradiation of an unsaturated monomer and of the polysaccharide allowed initiating the free radical polymerization of the monomer onto the polysaccharide's backbone. This method has been successfully used to graft acrylic acid onto carboxymethylcellulose [16] and also Nisopropylacrylamide onto alginate original structures [17].

\footnotetext{
* Corresponding author. Tel.: +351 239798700; fax: +351239798703

E-mail address: pferreira@eq.uc.pt (P. Ferreira).
}

Dextran is a polysaccharide consisting of $\alpha-1,6$ linked $D-$ glucopyranese, with some degree of branching via $\alpha-1,3$ linkage, produced chemically or by bacteria from sucrose [14]. This natural polymer has been reported as an important material in the biomedical field [18] and has been applied as plasma expander [19] and in the development of drug delivery systems [20], hydrogels [21] and wound dressings [22] among others.

Poly(N-isopropylacrylamide) (PNIPAAm) has been largely applied in the preparation of hydrogels, especially when a thermalresponsive behaviour is desired. This polymer's sensitivity to temperature is due to a thermal transition occurring at $32.5^{\circ} \mathrm{C}$ which is defined as the lower critical solution temperature (LCST) [23]. This property is mainly attributed to changes in the balance between hydrophilic and hydrophobic forces with the molecules in the surrounding medium and the break of hydrogen bonds between PNIPAAm and water molecules [24]. This phenomena result in a precipitation and dissolution cycle which occurs with temperature upon heating and cooling, respectively. Based on this characteristic, PNIPAAm has been used in several applications in the drug delivery systems area, namely, in temperature controlled systems [25-27].

During this study, hydrogel membranes were prepared by grafting and crosslinking NIPAAm and dextran using gamma radiation. These materials presented thermal-sensitive behaviour due to the presence of PNIPAAm in their structure. The membranes were characterized by ATR-FTIR, elemental analysis and by determining their LCTS and swelling capacity, as well as their surface energies. Finally, membranes containing the drug Ondansetron ${ }^{\mathrm{TM}}$ (an antiemetic used to treat nausea and vomiting, frequently following chemotherapy) were also prepared and the drug release 
profile was determined at two different temperature values: 25 and $37^{\circ} \mathrm{C}$.

\section{Experimental procedure}

\subsection{Materials}

Dextran (MW =5,000,000-40,000,000) was purchased from Sigma (Steinheim, Germany). N-isopropylacrylamide, 97\% (EC 218638-5) was purchased from Aldrich (Steinheim, Germany). Acetic acid, with a degree of purity of $99.5 \%$, was acquired from BHDChemical Lda (Poole, UK).

The drug used in this study was Ondansetron ${ }^{\mathrm{TM}}$, obtained from Hospital Garcia de Orta (Almada, Portugal) and was used throughout the assays as the commercial solution.

Dialysis membranes (12-14 kD) were acquired from Spectrum (Gardena, USA).

\subsection{Membranes preparation}

Dextran solution was prepared by dissolving $1 \mathrm{~g}$ of dextran in $50 \mathrm{~mL}$ of distillate water at room temperature, under mechanical stirring for $30 \mathrm{~min}$. Afterwards, $1 \mathrm{~g}$ of $\mathrm{N}$-isopropylacrylamide was added to the solution which was continuously stirred at room temperature for another $10 \mathrm{~min}$. The mixture was then placed in Amilon polyamide bags, under nitrogen atmosphere and irradiated at the ${ }^{60}$ Co Portuguese irradiation facility at the Nuclear and Technological Institute in Sacavém. In order to avoid extended chain scission, mixtures were exposed to a dosing level of gamma radiation of $5 \mathrm{kGy}$. Samples were irradiated parallel to the irradiator and the irradiation dosage was measured with amber and red Perspex dosimeters (Harwell).

Different irradiation times were tested: 1, 2, 3, 4 and $5 \mathrm{~h}$. For these reason, the obtained membranes will be named DexP1, DexP2, DexP3, DexP4 and DexP5, respectively. Once prepared, these membranes were inserted in dialysis membranes and washed against distillate water for $24 \mathrm{~h}$ in a stirred vessel to extract the non-reacted monomer.

\subsection{ATR-FTIR analyses}

All the samples were analyzed by the ATR-FTIR technique in order to confirm the inclusion of NIPAAm in the polymeric structure. All the analyses were performed on a Magma-IR ${ }^{\mathrm{TM}} \mathrm{Spec}$ trometer 750 from Nicolet Instrument Corp., equipped with a Golden Gate Single Reflection Diamond ATR. Spectra were recorded on an average of 128 scans at a resolution of $4 \mathrm{~cm}^{-1}$.

\subsection{Elemental analysis}

This technique was used to determine the percentage weight of nitrogen $(\mathrm{N})$ in the final materials after reaction of dextran with NIPAAm at various irradiation times.

All the membranes were freeze-dried and lyophilized and the obtained powder was then analyzed using a Fisions Instruments EA-1108.

\subsection{LCST determination}

The lower critical solution temperature (LCST) was evaluated following the transmittance of the samples at $500 \mathrm{~nm}$ in a Jasco V530 Spectrophotometer and heating the solutions in a thermostatic bath from $25^{\circ} \mathrm{C}$ to $40^{\circ} \mathrm{C}$ in steps of $1^{\circ} \mathrm{C}$. Transmittance values were measured for three samples of each film at all values of temperature

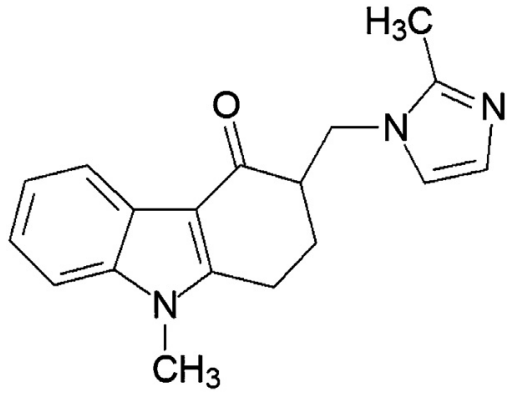

Fig. 1. Chemical structure of Ondansetron ${ }^{\mathrm{TM}}$.

after stabilizing the samples for $30 \mathrm{~min}$. LCST was inferred from the inflexion point of the transmittance vs. temperature curve.

\subsection{Swelling capacity in physiological serum}

Three samples of each membrane were previously dried until constant weight at $40^{\circ} \mathrm{C}$ under vacuum conditions. The weight of the dried samples was obtained $\left(W_{d}\right)$.

These samples were then immersed in physiological serum $(\mathrm{pH}=7.4)$ at 25 and $37^{\circ} \mathrm{C}$ and, at predetermined times, the samples were removed and weighted until constant weight was achieved $\left(W_{S}\right)$. The swelling ratio was evaluated by using Eq. (1).

Swelling ratio $(\%)=\left(\frac{W_{s}-W_{d}}{W_{d}}\right) \times 100$

\subsection{Determination of water contact angle and surface energy}

During this work, water contact angles as well as surface energies were determined for the prepared membranes. These parameters were evaluated by static contact angle $(\theta)$ measurements in a DAS 1 from Kruss in order to compare them with the ones obtained from literature for skin. All the tests were performed on the air-facing surfaces of the samples with four liquids: water, formamide, ethylene glycol and propylene glycol using the sessile drop method. Nine measurements on different points were performed to calculate the mean static contact angle $\theta$ and its standard deviation. The dispersive $\gamma_{S}^{D}$ and polar $\gamma_{S}^{P}$ components of the surface energy were determined according to the Owens-Wendt-Rabel and Kaelble relationship.

\subsection{Release pattern}

A drug delivery system was developed using the membranes previously prepared. The chosen drug was Ondansetron ${ }^{\mathrm{TM}}$ (Fig. 1), which is an antiemetic as previously described.

Three samples of each membrane were immersed in $5 \mathrm{~mL}$ of a drug solution $(2 \mathrm{mg} / \mathrm{mL})$ for 7 days. After this time, the remaining concentration of the solution was measured by UV-vis spectroscopy, using a Jasco V-530 spectrophotometer. The absorbed drug concentration was then calculated as the difference between the initial and the final drug concentration in the solution.

The quantification of the amount of drug released as a function of time was performed using the same spectrophotometer. The films were introduced in a dialysis membrane (to avoid any piece of the film interfering in the reading) and then inserted in erlemeyers containing $100 \mathrm{~mL}$ of physiological serum. Each assay was carried out at 25 and $37^{\circ} \mathrm{C}$. Absorbance values were obtained at $312 \mathrm{~nm}$ (maximum of the drug absorption spectra), at predetermined time intervals, until a maximum of $170 \mathrm{~h}$. 


\section{Results and discussion}

The preparation of the membranes was performed by simultaneous grafting/crosslinking of dextran in the presence of NIPAAm. These reactions were accomplished by irradiating the materials with gamma radiation, a high-energy ionizing radiation.

\subsection{ATR-FTIR analysis}

The grafting of NIPAAm onto the structure of dextran was confirmed by ATR-FTIR. Fig. 2 presents the ATR-FTIR spectra obtained for dextran and its derivatives DexP1 and DexP5 since they represent the lower and the higher irradiation times and are the ones with the most significant differences. The spectra of both membranes presented the same bands, with some differences in their intensity.

The spectrum of dextran showed the following relevant bands: $\sim 3300 \mathrm{~cm}^{-1}(\mathrm{O}-\mathrm{H}$ stretching vibrations $), \sim 2922 \mathrm{~cm}^{-1}$ (C-H stretching), $\sim 1640 \mathrm{~cm}^{-1}$ (O-H bonding), $1150 \mathrm{~cm}^{-1}$ (C-O-C stretching) and a sharp band at $\sim 1020 \mathrm{~cm}^{-1}$ (stretching vibration of the hydroxyl group) [28]. Spectrum of NIPAAm presents a sharp peak at $\sim 3280 \mathrm{~cm}^{-1}$ ( $\mathrm{N}-\mathrm{H}$ stretching vibration), a peak at $2960 \mathrm{~cm}^{-1}$ ( $-\mathrm{H}$ stretching) and the typical amide I and II bands at $\sim 1650 \mathrm{~cm}^{-1}$ and $1550 \mathrm{~cm}^{-1}$ (due to $\mathrm{C}=\mathrm{O}$ stretching and $\mathrm{N}-\mathrm{H}$ bending, respectively) [29].

As can been seen in Fig. 2, in the spectra of modified dextran, independently of the reaction time, a new band at $\sim 1540 \mathrm{~cm}^{-1}$ can be observed, which corresponds to the $\mathrm{N}-\mathrm{H}$ vibration of NIPAAm. Also, the band at $1640 \mathrm{~cm}^{-1}$ (already present at the original dextran), became more intense, since NIPAAm presents a band at the same wavenumber which refers to $\mathrm{C}=\mathrm{O}$ stretching of NIPAAm. It was also observed that both bands increased their intensity with longer reaction times due to the increase of NIPAAm concentration in the final membranes.

\subsection{Elemental analysis}

This technique was used to confirm NIPAAm grafting onto the structure of dextran, by the detection and quantification of the \% of nitrogen $(\mathrm{N})$. For that purpose, a film prepared with unmodified dextran was used as a negative control. Elemental analysis was also used to quantify the percentage of nitrogen in the membranes obtained for all the tested irradiation times. Fig. 3 represents de variation of $\% \mathrm{~N}$ determined in the samples with irradiation time.

By analyzing Fig. 3 it is possible to verify that, unlike unmodified dextran (with \% $\mathrm{N}$ of $0 \%$ ), all the membranes presented nitrogen in their composition which suggests that grafting was well succeeded. It is also possible to observe that the total amount of $\mathrm{N}$ present in the modified dextran increases with irradiation time. These results suggest that the reaction time influenced the degree of substitution, which was higher for longer periods. Similar correspondences between irradiation time and grafting yield were previously obtained for different polymers by other authors [30,31].

\subsection{LCST determination}

Fig. 4 shows the optical transmittance curves for dextran, PNIPAAm, DexP1 and DexP5.

The values represent the mean value of transmittance at each measurement point. Standard deviations are not represented because of their very small value (between 0.02 and 0.08 ).

As can be seen in Fig. 4, a sharp decrease in optical transmittance of all systems containing PNIPAAm occurred at a specific temperature value, i.e., all systems except dextran presented a temperature sensitive behaviour (and consequently a LCST). The lowest LCTS value was obtained for pure PNIPAAm, ca. $32-33^{\circ} \mathrm{C}$, which is in
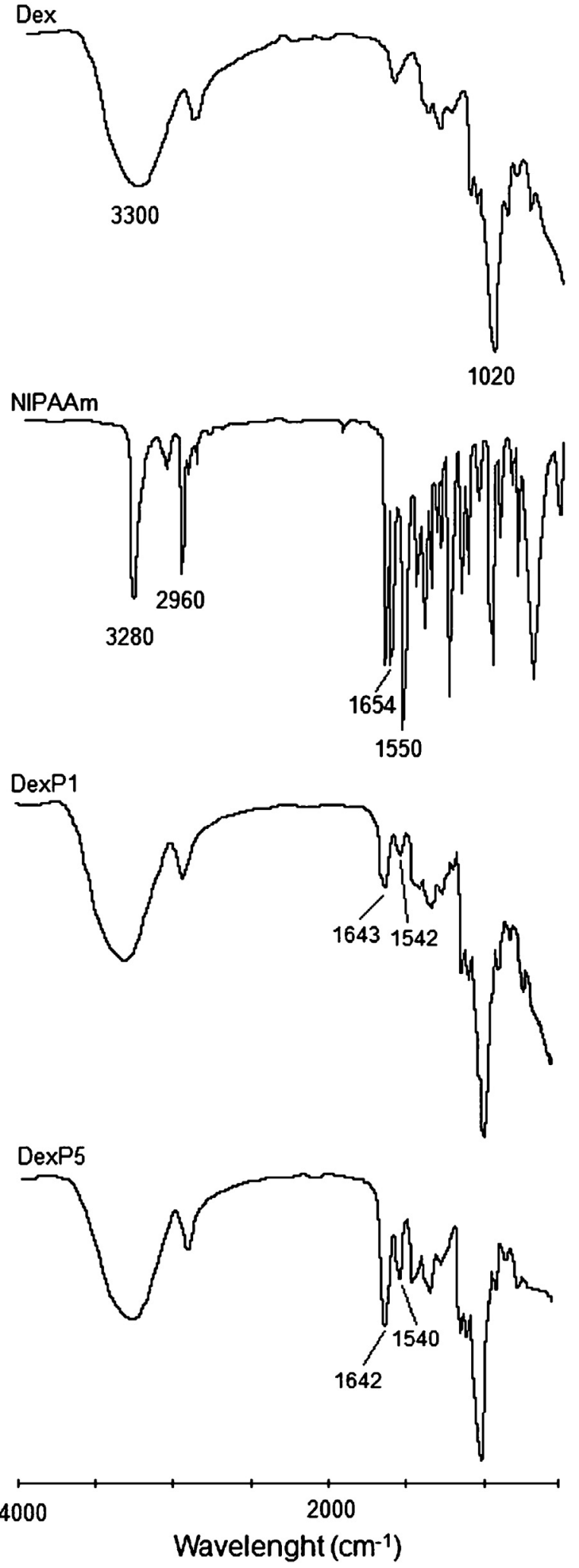

Fig. 2. ATR-FTIR spectra of dextran and of DexP1 and DexP5 membranes.

accordance with literature values [32]. For DexP1 and DexP5 the LCST presented a small increase when compared with PNIPAAm (approximately $35^{\circ} \mathrm{C}$ ). This shift in LCTS value is mainly due to the presence of the hydrophilic part of dextran in the gels. This variation is consistent with the works presented by other authors who reported similar results [33]. 


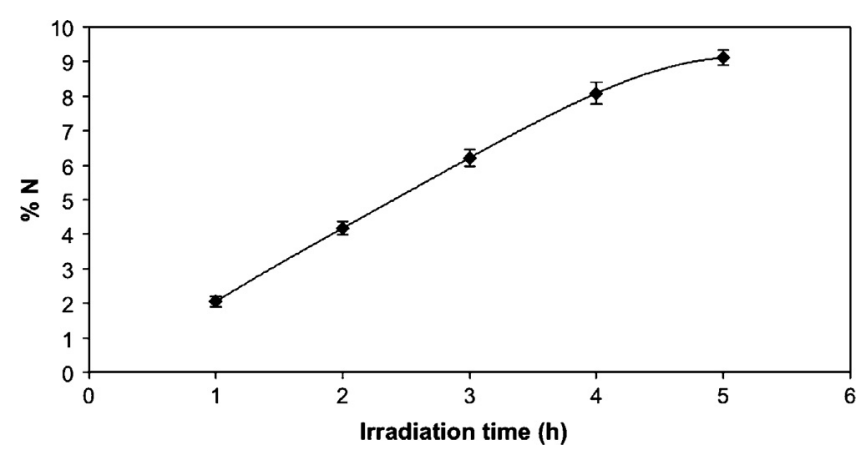

Fig. 3. Variation of the $\% \mathrm{~N}$ with the irradiation time for unmodified and NIPAAm grafted dextran membranes.

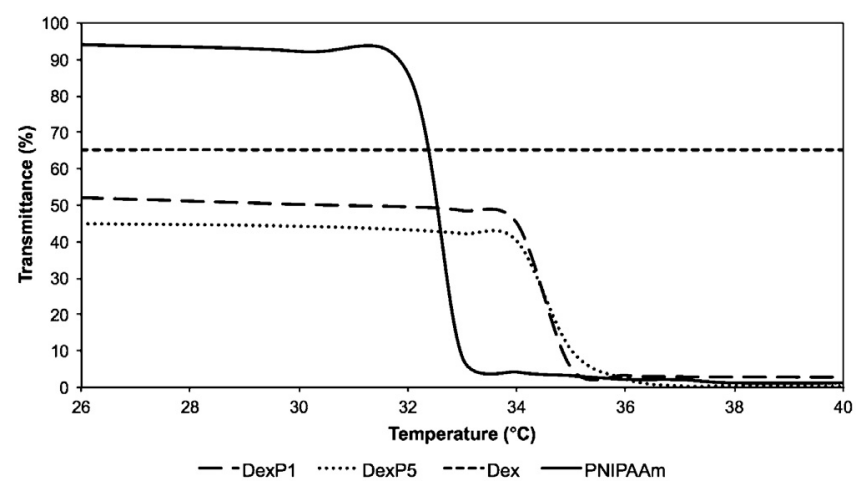

Fig. 4. Optical transmittance values obtained with temperature for dextran, PNIPAAm, DexP1 and DexP5.

Table 1

Swelling capacity values for dextran based membranes obtained in physiological serum $(\mathrm{pH}=7.4)$ at 25 and $37^{\circ} \mathrm{C}$.

\begin{tabular}{lll}
\hline System & \multicolumn{2}{l}{ Swelling capacity (\%) } \\
\cline { 2 - 3 } & $25^{\circ} \mathrm{C}$ & $37^{\circ} \mathrm{C}$ \\
\hline DexP1 & 166 & 65 \\
DexP2 & 174 & 62 \\
DexP3 & 183 & 55 \\
DexP4 & 189 & 47 \\
DexP5 & 203 & 40 \\
\hline
\end{tabular}

\subsection{Swelling capacity}

Swelling of the samples was evaluated in physiological serum at 25 and $37^{\circ} \mathrm{C}$. All the membranes achieved maximum swelling after one week of incubation despite the temperature. Values of swelling (\%) for all the prepared membranes are presented in Table 1.

The results presented in Table 1 show that, regardless the test temperature, the membranes present hydrogel behaviour. Also, it is visible that, at $25^{\circ} \mathrm{C}$, swelling capacity increases with irradiation time. This suggests that higher reaction times allow higher incorporation of hydrophilic groups in the final polymeric network. This conclusion is consistent with ATR-FTIR and elemental analysis results. However, a different outcome was observed at $37^{\circ} \mathrm{C}$. At this temperature, swelling capacity decreases at all times for both samples. Also, the inverse correlation between irradiation time and swelling capacity is verified at $37^{\circ} \mathrm{C}$. At this temperature, the higher the amount of PNIPAAm incorporated in the polymeric structure, the lower their hydrophilicity becomes. These two markedly different behaviours can be explained by the fact that at $37^{\circ} \mathrm{C}$ the systems were above the LCTS value of PNIPAAm. At $37^{\circ} \mathrm{C}$ there is an increase of the intramolecular interactions involving PNIPAAm segments on the gel which precludes water from the precipitated/collapsed segments of PNIPAAm leading to the observed differences [34]. This also elucidates why the system with higher substitution degree is the one presenting the lowest value of swelling.

\subsection{Determination of water contact angle and surface energy}

Water contact angles $(\theta)$ were measured for the prepared membranes using different irradiation times and at two temperature values: 25 and $37^{\circ} \mathrm{C}$ (Table 2). At $25^{\circ} \mathrm{C}$ those values varied between $68.9^{\circ}$ and $55.8^{\circ}$ for DexP1 and DexP5 and between $110.5^{\circ}$ and $137.5^{\circ}$ for the same membranes at $37^{\circ} \mathrm{C}$. These results support the conclusions taken from the swelling capacity, e.g., all systems presented high hydrophilicity levels depending on irradiation time/substitution degree and also depending on the temperature of the assay. We verified that the systems with higher degree of substitution presented a more accentuated temperature depending behaviour which is consistent with the higher concentration of PNIPAAm in the final structure of the material.

The surface energy values for each prepared membrane were also determined according to the Owens-Wendt-Rabel and Kaelble relationship. According to Owens, Wendt, Rabel and Kaelble the interfacial tension can be divided in two components: dispersive interactions and polar interactions [35]. Polar interactions comprise Coulomb interactions between permanent dipoles and the ones between permanent and induced dipoles. The interactions caused by time fluctuations of the charge distribution within the molecules are called dispersive interactions.

The main purpose of this study was to determine if the crosslinked membranes would easily adhere when placed over skin. Surface energy of skin varies between 38 and $56 \mathrm{mN} / \mathrm{m}$ depending on its temperature and relative humidity [36]. According to a fundamental thermodynamic principle, membranes will adhere to skin if their surface energy is equal or lower than these values [36]. The measured values for surface energies at 25 and $37^{\circ} \mathrm{C}$ are presented in Table 2 .

As a general conclusion by analysing Table 2 it is possible to say that surface energies are very similar for all the membranes at both tested temperatures. However, significant differences on their components were observed. At $25^{\circ} \mathrm{C}$, the polar component increases with irradiation time, which means that hydrophilicity increases with grafting degree. These results are associated with the incorporation of hydrophilic groups of NIPAAm onto dextran structure and also with the fact that, at this temperature vale, PNIPAAm is under its LCTS. The opposite behaviour is verified at $37^{\circ} \mathrm{C}$. At this temperature, the values of the dispersive components are higher than at $25^{\circ} \mathrm{C}$ for all the membranes. This effect is related with the thermal behaviour induced by PNIPAAm and suggests an increase in the hydrophobicity associated with the precipitation/aggregation of PNIPAAm. This is more significant for higher substitution degrees and therefore the dispersive component increases with irradiation time.

Nevertheless, at any of the tested temperatures the surface energies of the prepared membranes are lower than the ones mentioned for skin. These values suggest that adhesive forces between the polymeric matrices and the skin will prevail against the intermolecular forces of the materials, resulting in the adherence of the membranes to the epidermis.

\subsection{Release pattern}

Release studies were performed by UV spectroscopy and the amount of drug released by each system was evaluated using a validated calibration curve at $312 \mathrm{~nm}$. The final amount of drug was expressed as a percentage of the initial drug amount introduced in the gel. The drugs' release kinetics study was based in the proposal 
Table 2

Values of water contact angle and surface free energy $\left(\gamma_{S}\right)$, dispersive $\left(\gamma_{S}^{D}\right)$ and polar components $\left(\gamma_{S}^{P}\right)$ of the surface free energy of the dextran based membranes.

\begin{tabular}{|c|c|c|c|c|c|c|c|c|}
\hline \multirow[t]{2}{*}{ System } & \multicolumn{4}{|c|}{$25^{\circ} \mathrm{C}$} & \multicolumn{4}{|l|}{$37^{\circ} \mathrm{C}$} \\
\hline & $\theta\left(^{\circ}\right)$ & $\gamma_{S}(\mathrm{mN} / \mathrm{m})$ & $\gamma_{S}^{D}(\mathrm{mN} / \mathrm{m})$ & $\gamma_{S}^{P}(\mathrm{mN} / \mathrm{m})$ & $\theta\left(^{\circ}\right)$ & $\gamma_{S}(\mathrm{mN} / \mathrm{m})$ & $\gamma_{S}^{D}(\mathrm{mN} / \mathrm{m})$ & $\gamma_{S}^{P}(\mathrm{mN} / \mathrm{m})$ \\
\hline DexP1 & 68.9 & 29.4 & 8.8 & 20.6 & 110.5 & 24.9 & 9.8 & 15.1 \\
\hline DexP2 & 66.3 & 30.1 & 7.9 & 22.2 & 122.1 & 24.6 & 10.0 & 14.6 \\
\hline DexP3 & 62.0 & 31.2 & 6.7 & 24.5 & 126.7 & 24.0 & 10.1 & 13.9 \\
\hline DexP4 & 59.5 & 31.9 & 6.2 & 25.7 & 131.4 & 23.6 & 11.3 & 12.3 \\
\hline DexP5 & 55.8 & 32.3 & 5.9 & 26.4 & 137.5 & 23.2 & 12.4 & 10.8 \\
\hline
\end{tabular}

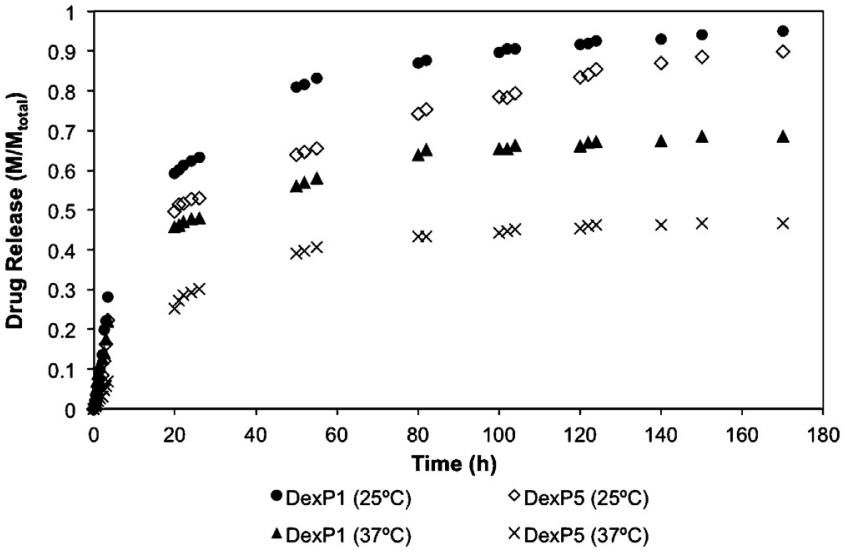

Fig. 5. Release pattern of Ondansetron ${ }^{\mathrm{TM}}$ from dextran based membranes DExP1 and DexP5 at temperatures values of 25 and $37^{\circ} \mathrm{C}$.

of Ritger and Peppas [37] where the quantity of drug release from the polymeric matrix is analyzed according to Eq. (2):

$\frac{M_{t}}{M_{\infty}}=k t^{n}$

where $M_{t}$ is the amount of drug release at a given $t$ time, $M_{\infty}$ is the total amount of drug used in the preparation of gels, $k$ is the kinetic constant, $t$ is time and $n$ is the diffusional exponent which is indicative of the release kinetics order. In this equation $M_{t} / M_{\infty}$ represents the fractional release. Eq. (2) has been frequently used in the literature since it provides information on diffusional mechanism. A value of $n=0.5$ indicates a Fickian diffusion process and $n=1$ indicates Case II transport in anomalous diffusion.

Fig. 5 shows the drug release pattern for the prepared membranes at 25 and $37^{\circ} \mathrm{C}$.

The results represent the mean value of three samples. Standard deviation values were calculated but were all below 0.2 . Therefore, they are not represented in order to simplify the results interpretation. Also, only the membranes with the higher and lower PNIPAAm graft degree are represented, since the other systems presented intermediate values.

By observing Fig. 5, it is perceptible that drug release is significantly higher at $25^{\circ} \mathrm{C}$ independently of PNIPAAm graft degree. These results are consistent with the ones registered and previously described for swelling. It is also possible to observe that, at $25^{\circ} \mathrm{C}$, and after $170 \mathrm{~h}$ of incubation, the amount of Ondansetron ${ }^{\mathrm{TM}}$ released was nearly $100 \%$ of the amount initially entrapped in both membranes. The results also showed that the gel with the highest degree of substitution (DexP5) was the one presenting a slightly lower drug release rate. This result suggests that the total concentration of PNIPAAm in the membranes influences the release of the entrapped drug. This effect may be due to the increase in the crosslinking degree of the membrane, causing a higher retention of drug inside the polymeric matrix. However, these differences are more notorious in the beginning of experiment since at the end of the measurements the amount of drug released was very
Table 3

Results obtained for the release exponent, the kinetic constant and the correlation coefficient for Ondansetron ${ }^{\mathrm{TM}}$.

\begin{tabular}{llllllll}
\hline System & $25{ }^{\circ} \mathrm{C}$ & & & & $37{ }^{\circ} \mathrm{C}$ & & \\
\cline { 2 - 3 } & $n$ & $k\left(h^{n}\right)$ & $R^{2}$ & & $n$ & $k\left(h^{n}\right)$ & $R^{2}$ \\
\hline DexP1 & 0.528 & 0.0590 & 0.884 & & 0.528 & 0.0570 & 0.892 \\
DexP2 & 0.545 & 0.0613 & 0.951 & & 0.568 & 0.0503 & 0.900 \\
DexP3 & 0.551 & 0.0602 & 0.931 & & 0.566 & 0.0413 & 0.942 \\
DexP4 & 0.550 & 0.0623 & 0.955 & & 0.578 & 0.0330 & 0.945 \\
DexP5 & 0.554 & 0.0613 & 0.960 & & 0.633 & 0.0212 & 0.948 \\
\hline
\end{tabular}

similar at $25^{\circ} \mathrm{C}$. The influence of the concentration of PNIPAAm in the release of the drug is more easily noticed when analysing the curves for the temperature of $37^{\circ} \mathrm{C}$. In this case, it was verified that the system containing higher concentration of PNIPAAm presented a lower amount of drug release. This result is in conformity with the values registered for swelling and described previously. Also, previous studies reported comparable release profiles using PNIPAAm grafted dextran membranes prepared by photocrosslinking [38].

The release exponent $(n)$, the kinetic constant $(k)$ and the correlation coefficient $\left(R^{2}\right)$ were calculated using Eq. (2) and the obtained results are presented in Table 3.

As can be seen in Table 3 , at $25^{\circ} \mathrm{C}$, all the systems presented values for the release exponent close to 0.5 , suggesting a Fickian mechanism for the release of Ondansetron ${ }^{\mathrm{TM}}$, meaning that the diffusion of the drug molecules is the major mechanism behind the release. We can also see that the systems placed at $37^{\circ} \mathrm{C}$ generally present higher values for the exponent and that, at higher grafting degrees, the values obtained suggest a Non-Fickian release pattern, indicating some influence of the polymer relaxation process. These results are consistent with the ones obtained for the swelling capacity, where the results for $37^{\circ} \mathrm{C}$, showed also the influence of the precipitated polymer in this property.

\section{Conclusions}

During this work gamma radiation was used as the initiating system for the preparation of membranes using dextran and NIPAAm. The incorporation of PNIPAAm in the membranes was confirmed by ATR-FTIR and elemental analysis. It was possible to verify that different irradiation times lead to different amounts of PNIPAAm grafted in dextran and consequently to different system properties, including LSCT. Ultimately, this allows the tuning of the LCST according with the specific needs of the practical application. Swelling behaviour, surface energy and even drug release proved to be influenced by PNIPAAm concentration and consequently by the tested temperatures $\left(25\right.$ and $37^{\circ} \mathrm{C}$ ). Release patterns showed that, at $25^{\circ} \mathrm{C}$, the amount of drug released is higher than at $37^{\circ} \mathrm{C}$. These results suggest that composition, irradiation time and temperature of operation altogether can be controlled to tune the kinetics of drug release. 


\section{Acknowledgment}

The authors would like to thank Fundação para a Ciência e Tecnologia for the financial support to J.F. Almeida (SFRH/BD/19707/2004).

\section{References}

[1] H.K. Can, B.K. Denizli, A. Güner, Z.M.O. Rzaev, Carbohydrate Polymers 59 (2005) 51-56.

[2] T. Coviello, P. Matricardi, C. Marianecci, F. Alhaique, Journal of Controlled Release 119 (2007) 5-24.

[3] S.-E. Park, Y.-C. Nho, H.-I. Kim, Radiation Physics and Chemistry 69 (2004) 221-227.

[4] J. Trudel, S.P. Massia, Biomaterials 23 (2002) 3299-3307.

[5] M.A. Abd El-Ghaffar, M.S. Hashem, M.K. El-Awady, A.M. Rabie, Carbohydrate Polymers 89 (2012) 667-675.

[6] A. Martínez-Ruvalcaba, E. Chornet, D. Rodrigue, Carbohydrate Polymers 67 (2007) 586-595.

[7] J.B. Leach, C.E. Schmidt, Biomaterials 26 (2005) 125-135.

[8] L. Almany, D. Seliktar, Biomaterials 26 (2005) 2467-2477.

[9] A.S. Hoffman, Advanced Drug Delivery Reviews 43 (2002) 3-12.

[10] K. Ulbrich, V. Subr, P. Podpěrová, M. Burešová, Journal of Controlled Release 34 (1995) 155-165.

[11] Y.D. Livney, O. Ramon, E. Kesselman, U. Cogan, S. Mizrahi, Y. Cohen, Journal of Polymer Science: Polymer Physics 39 (2001) 2740-2750.

[12] L. Verestiuc, C. Ivanov, E. Barbu, J. Tsibouklis, International Journal of Pharmaceutics 269 (2004) 185-194.

[13] M. Torres-Lugo, N.A. Peppas, Macromolecules 32 (1999) 6646-6651.

[14] L. Ferreira, M.H. Gil, J.S. Dordick, Biomaterials 23 (2002) 3957-3967.

[15] M.H. Casimiro, J.P. Leal, M.H. Gil, Nuclear Instruments and Methods B 236 (2005) 482-487.

[16] H.M. Said, S.G.A. Alla, A.W.M. El-Naggar, Reactive and Functional Polymers 61 (2004) 397-404.
[17] S.B. Lee, E.K. Park, Y.M. Lim, S.K. Cho, S.Y. Kim, Y.M. Lee, Y.C. Nho, Journal of Applied Polymer Science 100 (2006) 4439-4446.

[18] J. Maia, L. Ferreira, R. Carvalho, M.A. Ramos, M.H. Gil, Polymer 46 (2005) 9604-9614.

[19] R. McCahon, J. Hardman, Anaesthesia and Intensive Care 11 (2010) 75-77.

[20] M.A. Casadei, F. Cerreto, S. Cesa, M. Giannuzzo, M. Feeney, C. Marianecci, P. Paolicelli, International Journal of Pharmaceutics 325 (2006) 140-146.

[21] L. Weng, A. Romanov, J. Rooney, W. Chen, Biomaterials 29 (2008) 3905-3913.

[22] J.G. Clay, D. Zierold, K. Grayson, F.D. Battistella, Journal of Surgical Research 155 (2009) 89-93.

[23] R. Salgado-Rodriguez, A. Licea-Claverie, K.F. Arndt, European Polymer Journal 40 (2004) 1931-1946.

[24] C.D. Vo, D. Kuckling, H.-J.P. Adler, M. Schönhoff, Colloid and Polymer Science 280 (2002) 400-409.

[25] D. Schmaljohann, Advanced Drug Delivery Reviews 58 (2006) 1655-1670.

[26] C. He, S.W. Kim, D.S. Lee, Journal of Controlled Release 127 (May (3)) (2008) 189-207.

[27] T. Zhang, G. Li, L. Guo, H. Chen, International Journal of Biological Macromolecules 51 (2012) 1109-1115.

[28] X. Li, W. Liu, G. Ye, B. Zhang, D. Zhu, K. Yao, Z. Liu, X. Sheng, Biomaterials 26 (2005) 7002-7011.

[29] Y. Katsumoto, T. Tanaka, H. Sato, Y. Ozaki, Journal of Physical Chemistry A 106 (2002) 3429-3435

[30] J. Chen, L. Yang, Y.C. Nho, A.S. Hoffman, Preparation of blood compatible hydrogels by preirradiation grafting techniques, in: N. Ashammakhi, R. Reis, F. Chiellini (Eds.), Topics in Tissue Engineering, 4, 2008, pp. 1-41 (Chapter 14).

[31] F. Ranogajec, M. Mlinac-Misak, Z. Hell, Polimeri 29 (2008) 236-243.

[32] K. Van de Velde, P. Kiekens, Carbohydrate Polymers 58 (2004) 409-416.

[33] S.R.V. Tomme, W.E. Hennink, Expert Review of Medical Devices 4 (2007) $147-164$.

[34] B. Jeong, S.W. Kim, Y.H. Bae, Advanced Drug Delivery Reviews 54 (2002) 37-51.

[35] D. Owens, R. Wendt, Journal of Applied Polymer Science 13 (1969) 1711-1717.

[36] S. Venkatraman, R. Gale, Biomaterials 19 (1999) 1119-1136.

[37] P.L. Ritger, N.A. Peppas, Journal of Controlled Release 5 (1987) 23-36.

[38] J.F. Almeida, P. Ferreira, A. Lopes, M.H. Gil, International Journal of Biological Macromolecules 49 (2011) 948-954. 